\title{
Prenatal and puerperal care and indicators of severity: a study about the information available on pregnant women's card
}

Ivelise Araújo de Souza 1

https://orcid.org/0000-0002-2858-9983

Mário Ivo Serinolli 2

iD https://orcid.org/0000-0002-2137-7814

Márcia Cristina Zago Novaretti 3

https://orcid.org/0000-0002-4802-8446 1-3 Programa de Mestrado Profissional em Administração - Gestão em Sistemas de Saúde (PMPA-GSS). Universidade Nove de Julho. Rua Vergueiro, 245. Campus Vergueiro.
São Paulo, SP, Brasil. CEP: 01.504-000. E-mail: mserinolli@gmail.com

\begin{abstract}
Objectives: to identify and to discuss the frequency of the prenatal and puerperal care of pregnant women from the eastern zone of São Paulo city, São Paulo State, Brazil, categorizing it according to the Kessner Index modified in 1993 by Takeda. We used the data available on the card of pregnant woman and the discharge summaries, correlating the results with the indicators of severity in childbirth.

Methods: this is a descriptive, cross-sectional quantitative study based on the analysis of the variables of the pregnant woman's card and the diagnoses identified in the discharge summaries. Data were collected through a field survey conducted in the Eastern zone of the city of São Paulo city, São Paulo State, Brazil. A statistical analysis was used to identify associations between the categorization and the severity indicators listed in the discharge summaries.

Results: it was observed that prenatal care in the Eastern zone of São Paulo city, São Paulo State, Brazil was classified as intermediate (56.9\%) in the majority of women. Regarding this categorization with the severity indicators, there is a higher incidence of risks for inappropriate categorization (8.89\%) when compared to the appropriate (1.67\%) and the intermediate (4.44\%) ones.

Conclusions: it was possible to conclude that the more adequate prenatal care, the lower the chances of unfavorable outcomes and incidence of risks.

Key words Health management, Public health, Prenatal care, Risk factors, Pregnancy
\end{abstract}

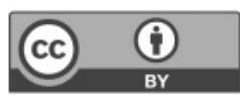




\section{Introduction}

Although there was a considerable reduction in the mortality rate in Brazil from 1990 to 2012, going from 140 deaths per 100,000 live births to 68 deaths per 100,000 live births, 1,2 according to World Health Organization, 3 recently, it has been observed a reduction in the pace of this slowdown and new strategies need to be revised in order to accelerate this process, given that the target agreed for 2015 was 35 deaths per 100,000 live births. Thus, the importance of adequate prenatal care, which consists in preventing, diagnosing and treating undesirable events during pregnancy, childbirth and the puerperium, is confirmed. This qualified care is fundamental for reducing maternal and child morbidity and mortality, therefore the quality of prenatal care is directly related to the integral health of mothers and theirfetuses. 4

Furthermore, the analysis of the information collected on the pregnant woman's card and its evaluation according to classification standards that indicate the adequacy of this assistance. In addition, the importance of investigating whether the adequacy of prenatal or puerperal care is related, somehow, to the incidence of severity indicators, in order to propose actions for improvement and prevention of death.

Given the above, this study aimed to identify and discuss the frequency of prenatal and puerperal care of pregnant women in Eastern São Paulo, São Paulo State, Brazil, categorizing it according to the Kessner Index modified in 1993 by Takeda (IKT), 5 based on the data available on the card of the pregnant woman and the discharge summaries, correlating the results with the indicators of severity in childbirth.

\section{Methods}

This study adopted the descriptive and crosssectional quantitative methods and it was based on the analysis of the pregnant woman's card variables and the correlation of the results with the severity indicators identified in the discharge summary. The discharge summary analysis was performed by obstetrics professionals (doctors and nurses), who identified the severity indicators related to maternal morbidity.

The study was submitted to a human research ethics committee under the protocol CAAE no. 61427016.9.0000.5511, and authorized according to the opinion embodied in. 1.839 .620 of November 28, 2016. This study was carried out with 360 post- partum women from the Easternregion of São Paulo City, specifically from Sapopemba, Aricanduva, São Mateus and CidadeTiradentes neighborhoods.

The research population was defined by a sample calculation which assumed a simple random sampling on categorical variables, considering the $95 \%$ confidence level. According to DATASUS database, the region where the survey was conducted has an average of 1,100 deliveries per month. Considering, then, the average of deliveries performed in the region, it was necessary to investigate at least 285 postpartum women and, consequently, 285 pregnant women cards and 285 discharge summaries. The investigated population was expanded to 360 participants to establish a safety margin during the data analysis process.

Inclusion criteria were: a) women in the postpartum, above 35 weeks of pregnancy in order not to compromise the criteria for consultation evaluation and, consequently, the IKT analysis; b) in case of maternal death, a first degree relative or spouse represented the patient; c) women have had prenatal care in the public health network; d) women declared to live in the Eastern part of the city of São Paulo, São Paulo State; e)women should have a Pregnant Woman Card and discharge summary; f) No specific exclusion criteria needed to be met.

The following research instruments were used: a) photocopies of the Pregnant Woman's Card; b) photocopies of the discharge summary. In the present study, according to the established objectives, we analyzed only the following prenatal or puerperal follow-up variables:

a) Presence or absence of transfusion in the intrapartum or postpartum period;

b) Use or non-use of magnesium sulphate treatment;

c) Admission to the Neonatal Intensive Care Unit;

d) Admission to the Maternal Intensive Care Unit;

e) Presence or absence of neonatal infection;

f) Presence or absence of maternal infection;

g) Installation or not of central venous catheter;

h) Length of stay of the pregnant woman longer than seven days;

i) Outcome for maternal death;

j) Outcome for fetal death;

k) Stillbirth.

From the data collected, we analyzed the frequency of prenatal and puerperal care of participants, in relation to consultations and medical examinations. We also established the relationship between the IKT and the relevant variables for this 
categorization, in order to evaluate the assistance as adequate, intermediate or inadequate

IKT categorizes prenatal care as:

a) Appropriate: in the case of six or more consultations at a gestational age; starting before 20 weeks, plus routine examination;

b) Inadequate: starting after 28 weeks and or less than 3 consultations.

c) Intermediate: other situations.

Based on the categorization of care reported in the cases studied, the results were correlated with indicators of severity at delivery. Statistical calculations were performed using the STATA version 2014 program. To analyze the relationship between the categories classified by the IKT and the severity indicators, the Pearson method was used, and to analyze the individual significance of the severity indicators, the results were grouped into two groups. "inadequate" and "other" categories, and Fisher's exact test was then applied.

\section{Results}

From the photocopies of the Pregnant Woman`s Card and the discharge summaries of the 360 postpartum women participating in the research, it was possible to gather the frequency information on prenatal and puerperal care regarding consultations and exams, presented in Table 1.

It has been noticed that only $15.3 \%$ of the pregnant women had a minimum of six consultations and all the basic exams; $56.9 \%$ of the pregnant women had a minimum of three appointments and a basic examination routine; and $27.8 \%$ had less than three consultations and no basic exam.

From the results of the analysis of prenatal and puerperal care, IKT was established for the cases studied (Table 1).

In this study, the results of the IKT categoriza- tion were also related to the severity indicators that are characterized as unexpected events in the pregnancy outcome and that were recorded in the Pregnant Woman Card or in the research participant's discharge summary, as presented in Table 2. It was found that the total incidence of severity indicators is lower $(\mathrm{n}=10)$ for cases categorized as adequate and higher in cases categorized as inadequate $(n=75)$. Among the cases categorized as inadequate, in which there was a higher incidence of severity indicators, we highlight hospitalization in the Neonatal ICU $(n=20)$ and length of stay over 7 days $(\mathrm{n}=20)$.

A statistical analysis of the individual significance of the severity indicators was performed, as well as the relationship between the categories classified by the IKT and the severity indicators, considering as indicators that were significant in relation to the categorization of the IKT: ICU Neo $(<0.001)$, ICU (0.04), Length of permanence greater than 7 days $(<0.001)$, Maternal Infection (0.002), Stillbirth (0.006) (Table 2).

Table 3 presents the analysis of risk incidence according to the categorization of prenatal and puerperal care considering the significance of risk factors. Considerable risk of severity was found in cases of prenatal and puerperal care categorized as inadequate $(8.89 \%)$, followed by cases classified as intermediate $(4.44 \%)$ and cases classified as adequate $(1.67 \%)$. The present study emphasized the importance of prenatal and puerperal care in the control of unfavorable events, also relating it to indicators of severity in childbirth and postpartum in cases studied in Eastern São Paulo, São Paulo, Brazil. It was evidenced that the assistance to pregnant women and mothers who were part of the study can be mostly classified as intermediate by performing the statistical investigation presented: $56.9 \%$ of care. In addition, it was noted that the

Table 1

Evaluation of the prenatal care process in the eastern part of the city of São Paulo, São Paulo State and categorization of care.

\begin{tabular}{lcc}
\hline Prenatal and puerperal care & $\mathbf{n}$ & \% \\
\hline Less than 3 consultations & 100 & 27.8 \\
Minimum number of 3 or more appointments and 1 exam routine & 205 & 56.9 \\
Minimum of 6 antenatal appointments and all basic exams & 55 & 15.3 \\
Total & 360 & 100.0 \\
Assist categorization & & 15.3 \\
Adequate & 55 & 56.9 \\
Intermediate & 205 & 27.8 \\
Inappropriate & 100 & 100.0 \\
Total & 360 & \\
\hline
\end{tabular}


percentage of care categorized as adequate $(15.3 \%)$ is lower when compared to those found in other regions of the City of São Paulo. 6

Regarding care categorized as inadequate $(27.8 \%)$, it was also found that they result in a higher risk for the presence of severity indicators, as these cases had a higher incidence of risk, at $8.89 \%$, followed by $4.44 \%$ in intermediate cases and $1.67 \%$ in appropriate cases.

Table 2

Relationship between severity indicators and the categorization of prenatal and puerperal care in the eastern part of São Paulo, São Paulo State (Sapopemba, Aricanduva, São Mateus and Cidade Tiradentes neighborhoods).

\begin{tabular}{|c|c|c|c|c|c|c|}
\hline & \multicolumn{6}{|c|}{ Kessner Index modified in 1993 by Takeda5 } \\
\hline & \multicolumn{2}{|c|}{ Adequate } & \multicolumn{2}{|c|}{ Intermediate } & \multicolumn{2}{|c|}{ Inappropriate } \\
\hline & $\mathrm{n}$ & $\%$ & $\mathrm{n}$ & $\%$ & $\mathrm{n}$ & $\%$ \\
\hline \multicolumn{7}{|l|}{ Outcome } \\
\hline \multicolumn{7}{|l|}{ Neo ICU* } \\
\hline Yes & 3 & 5.5 & 6 & 2.9 & 20 & 20.0 \\
\hline No & 52 & 94.5 & 199 & 97.1 & 80 & 80.0 \\
\hline \multicolumn{7}{|l|}{ Maternal ICU** } \\
\hline Yes & 0 & 0.0 & 3 & 1.5 & 5 & 5.0 \\
\hline No & 55 & 100.0 & 202 & 98.5 & 95 & 95.0 \\
\hline \multicolumn{7}{|l|}{ Sulfate } \\
\hline Yes & 1 & 1.8 & 5 & 2.4 & 2 & 2.0 \\
\hline No & 54 & 98.2 & 200 & 97.6 & 98 & 98.0 \\
\hline \multicolumn{7}{|l|}{ Transfusion } \\
\hline Yes & 1 & 1.8 & 2 & 1,0 & 3 & 3.0 \\
\hline No & 54 & 98.2 & 203 & 99.0 & 97 & 97.0 \\
\hline \multicolumn{7}{|l|}{ Central catheter } \\
\hline Yes & 0 & 0.0 & 0 & 0.0 & 2 & 2.0 \\
\hline No & 55 & 100.0 & 205 & 100.0 & 98 & 98.0 \\
\hline \multicolumn{7}{|l|}{ T.P. $>7$ days $* * *$} \\
\hline Yes & 1 & 1.8 & 4 & 2.0 & 20 & 20.0 \\
\hline No & 54 & 98.2 & 201 & 98.0 & 80 & 80.0 \\
\hline \multicolumn{7}{|l|}{ Maternal death } \\
\hline Yes & 0 & 0.0 & 1 & 0.5 & 2 & 2.0 \\
\hline No & 55 & 100.0 & 204 & 99.5 & 98 & 98.0 \\
\hline \multicolumn{7}{|l|}{ Fetal death } \\
\hline Yes & 1 & 1.8 & 2 & 1.0 & 4 & 4.0 \\
\hline No & 54 & 98.2 & 203 & 99.0 & 96 & 96.0 \\
\hline \multicolumn{7}{|l|}{ Stillborn $* * * *$} \\
\hline Yes & 0 & 0.0 & 0 & 0.0 & 4 & 4.0 \\
\hline No & 55 & 100.0 & 205 & 100.0 & 96 & 96.0 \\
\hline \multicolumn{7}{|c|}{ Neonatal infection } \\
\hline Yes & 2 & 3.6 & 2 & 1.0 & 5 & 5.0 \\
\hline No & 53 & 96.4 & 203 & 99.0 & 95 & 95.0 \\
\hline \multicolumn{7}{|c|}{ Maternal infection $* * * * *$} \\
\hline Yes & 1 & 1.8 & 2 & 1.0 & 8 & 8.0 \\
\hline No & 54 & 98.2 & 203 & 99.0 & 92 & 92.0 \\
\hline Total incidents & 10 & & 27 & & 75 & \\
\hline
\end{tabular}

* Fisher's exact test $p<0.001$ being grouped appropriate and intermediate IK; * Fisher's exact test $p=0.041$ being grouped appropriate and intermediate IK; $* * *$ Fisher's exact test $p<0.001$ being grouped appropriate and intermediate $\mathrm{IK} ; * * * *$ Fisher's exact test $p=0.006$ being grouped appropriate and intermediate IK; $* * * *$ Fisher's exact test $p=0.002$ being grouped appropriate and intermediate IK. 
Risk incidence according to the categorization of the Kessner Index modified in 1993 by Takeda 5 in prenatal and puerperal care in Eastern São Paulo - SP.

\begin{tabular}{lcccccc}
\hline & \multicolumn{5}{c}{ Kessner Index modified in 1993 by Takeda5 } \\
\cline { 2 - 7 } & \multicolumn{2}{c}{ Adequate } & \multicolumn{2}{c}{ Intermediate } & \multicolumn{2}{c}{ Inappropriate } \\
\cline { 2 - 7 } & $\mathrm{n}$ & $\%$ & $\mathrm{n}$ & $\%$ & $\mathrm{n}$ & $\%$ \\
\hline Presence of risk of severity & 49 & 13.61 & 189 & 52.50 & 68 & 18.69 \\
No & 6 & 1.67 & 16 & 4.44 & 32 & 8.89 \\
Yes & & & & & & \\
\hline
\end{tabular}

Pearson test $p<0.001$

\section{Discussion}

The pregnancy-puerperal process, although physiological, imposes on the organism innumerable adaptations that can place it in the pathological limit. For low-risk pregnancies; the Ministry of Health ${ }^{7}$ recommends a minimum of six consultations, one in the first trimester, and two in the second trimester and three in the third trimester. Thus, the results draw attention to the fact that the majority of pregnant women $(56.9 \%)$ had a minimum of three consultations and only one routine of exams, in contrast to the minimum recommended by the Prenatal Humanization Program and Birth (PHPN) of the Ministry of Health.

Unfavorable events and worse indicators of severity in childbirth and postpartum are associated with fewer than five consultations and when the pregnant woman does not receive qualified prenatal care, this compromises the gestational outcome. In addition, in a study conducted in 2008, Parada 8 identified that low coverage may be associated with the loss of records, failures, illegibility and early enrollment of pregnant women in prenatal care. Furthermore, health services should capture unregistered pregnant women, reduce the number of absentees, especially those at high risk, as well as monitor the evolution of pregnancy, including educational work with the pregnant woman and her entire family group. ${ }^{9}$

It is noteworthy that only $15.3 \%$ of the cases presented an adequate prenatal care, which is considered low compared to other regions of the city of São Paulo. 6 In two studies conducted at Hospital Amparo Maternal, which used the same criteria, an adequacy rate of $38.4 \%$ was found, which subsequently increased to $68.8 \% .10,11$ These authors agree with each other when referring to the fact that the recording of the results of the variables of the Pregnant Woman's Card is not influenced by factors external to the service, depending exclusively on minimum materials and, mainly, on the commitment of the professionals involved.

In the analysis of the performance of nurses from the eastern side of the city of São Paulo, Narchi12 states that they do not fully exercise their essential skills because they face institutional and personal barriers. The author concluded by highlighting the need for public policies to be revised with regard to improving maternal and child health care and the allocation of sufficient human resources for this area. 12

The categorization of prenatal and puerperal follow-ups as appropriate, intermediate and inadequate are relevant for assessing prenatal care, and the establishment of evaluation criteria and periodic monitoring of the way maternal care has been performed is of great importance. For Coutinho et $a l ., 13$ in a study that aimed to assess the adequacy of the prenatal care process among users of the Unified Health System in Juiz de Fora-MG, prenatal care performed in the city needed, at the time, to be revised in a qualitative way, including conducting periodic evaluations that could serve as an instrument to create improvement programs especially for the personnel involved in the process.

In an initial analysis, the severity indicator variables related toappropriate, intermediate and inadequate categorization according to IKT, shown in Table 2, indicate a gradual incidence of risk. Silva and Gois ${ }^{14}$ warn that low quality care is a factor of considerable influence on neonatal mortality rates, especially before one week of life.

Statistical analysis of risk incidence shows that the more appropriate or intermediate the assistance, the lower the likelihood of risk or the presence of severity indicators. Borbolato and Cardoso, 15 who sought to identify the impact of prenatal care on the prevention, for example, of premature birth, demonstrated that a number of factors are crucial to prevent the occurrence of the above-mentioned outcome, concluding that a minimal prenatal and well 
performed, as suggested by the Ministry of Health, is decisive for better results in the perinatal period.

From the results presented here, it is possible to conclude that the more adequate prenatal care is, the lower the chances of unfavorable outcomes and risk incidence (severity indicators). In a case-control study seeking to assess the rate of severe maternal morbidity in the Barbacena - MG microregion, Vidal et al. 16 found out that there is a considerable relationship between the factors of severity and the occurrence of adverse factors, especially maternal morbidity, stressing the importance of early identification of such factors in the search for strategies to prevent the occurrence of adverse factors.

It is important to note that, in general, the lack of registration on the Pregnant Woman's Card, as well as the failure to fill out the discharge summary, are factors that hinder data analysis and compromise the quality of prenatal care, putting at risk the safety of pregnant women and their babies.

The results of this study provide information that can be used by maternal and child health managers to guide maternal and child health policies and local actions for ongoing assessment sensitive to the identification of unfavorable outcomes in the pregnancypuerperal period.In addition, this study provides support for the awareness of the professionals involved to pay attention to the importance of filling in the variables of the Pregnant Woman's Card.

\section{References}

1. Soares VMN, Souza KV, Azevedo EMM, Possebon CR, Marques FF. Causas de mortalidade materna segundo níveis de complexidade hospitalar. Rev Bras Ginecol Obstetr. 2012; 34 (12): 536-43.

2. Brasil. Ministério da Saúde. Atenção ao pré-natal de baixo risco. Brasília, DF; 2012.

3. ONU (Organização das Nações Unidas). O Futuro que Queremos. Rio de Janeiro: ONU; 2012. [acesso em 19 setembro 2016]. Disponível em: www.onu.org.br/rio20/ img/2012/01/OFuturoqueQueremos_rascunho_zero.pdf.

4. Zanchi M, Gonçalves CV, Cesar JA, Dumith SC. Concordância entre informações do Cartão da Gestante e do recordatório materno entre puérperas de uma cidade brasileira de médio porte. Cad Saúde Pública. 2013; 29 (5): 1019-28.

5. Takeda S. Avaliação de unidade de atenção primária: a modificação dos indicadores de saúde e qualidade da atenção [dissertação]. Porto Alegre: Faculdade de Medicina da Universidade Federal de Pelotas; 1993.

6. Menezes Succi RC, Figueiredo EN, de Carvalho Zanatta L, Peixe MB, Rossi MB, Vianna LAC. Avaliação da assistência pré-natal em unidades básicas do município de São Paulo. Rev Latino-Am Enferm. 2008; 16 (6): 986-92.
It is noteworthy that this research is not exhaustive in itself, and more studies should be conducted for prenatal analysis, involving not only the quantitative analysis of data from primary documents, but also from secondary, associated with qualitative research. Among the main operational and methodological limitations of this study, we highlight the use of a sample, which, although significant, is only representative of a specific region of the country, despite the fact that the eastern part of São Paulo is a very populous region, with very peculiar characteristics.

Considering that the socioeconomic and demographic differences, as well as the conditions of access to health care, are significant factors for the increase of morbidity and mortality, the importance of this study is highlighted in a region where the persistent inequality gap describes the inadequate interlocution between primary, outpatient and hospital care services for pregnancy-puerperal care, 17 thus seeking to contribute to the formulation of new local strategies.

\section{Authors' contribution}

The authors contributed equally to the conception, data collection, evaluation of results, writing and final approval of the manuscript.

7. Brasil. Ministério da Saúde. Manual prático para a implementação da rede cegonha. Brasília, DF; 2011. [acesso em 20 setembro 2016]. Disponível em: www.saude.mt.gov.br/arquivo/3062.

8. Parada CMGL. Avaliação da assistência pré-natal e puerperal desenvolvidas em região do interior do Estado de São Paulo em 2005. Rev Bras Saúde Mater Infant. 2008; 8 (1): 113-24.

9. Cabral RWL, Medeiros AL, Pinto LNMR, Prado C, Durier IS. Atuação do enfermeiro nas intercorrências e complicações obstétricas durante o trabalho de parto e nascimento. In: Anais do VII Congresso de Enfermagem Obstétrica e Nacional; 2010; Londrina, Brasil.

10. Koffman MD, Bonadio IC. Avaliação da atenção pré-natal em uma instituição filantrópica da cidade de São Paulo. Rev Bras Saúde Mater Infant. 2005; 5 (Supl. 1): 23-32.

11. Castro FG, Kellison JG, Boyd SJ, Kopak A. A methodology for conducting integrative mixed methods research and data analyses. J Mix Methods Res. 2010; 4 (4): 342-60.

12. Narchi NZ. Atenção pré-natal por enfermeiros na zona leste da cidade de São Paulo. Rev Esc Enferm USP. 2010; 44 (2): 266-73.

13. Coutinho T, Teixeira MTB, Dain S, Sayd JD, Coutinho LM. Adequação do processo de assistência pré-natal entre as 
usuárias do Sistema Único de Saúde em Juiz de Fora - MG. Rev Bras Ginecol Obstet. 2003; 25(10): 717-24.

14. Silva APM, Gois RP. Fatores relacionados ao óbito hospitalar neonatal. Rev Med UFC. 2016; 56 (2): 16-20.

15. Borbolato BM, Cardoso MP. O impacto do pré-natal na prevenção do parto prematuro. Rev Thêma et Scientia. 2015; 5(1): 147-59.
16. Vidal CEL, Carvalho MAB, Grimaldi IR, Reis MC, Baêta MCN, Garcia RB, Silva SAR. Severe maternal morbidity in the microregion of Barbacena, Minas Gerais state, Brazil. Cad Saúde Coletiva. 2016; 24 (2): 131-8

17. Narchi NZ, Cruz EF, Gonçalves R. O papel das obstetrizes e enfermeiras obstetras na promoção da maternidade segura no Brasil. Ciênc Saúde Coletiva. 2013; 18 (4): 1059-68.

Received on April 24, 2018

Final version presented on June 21, 2019

Approved on August 2, 2019 